\title{
Ambiguidade pandêmica: um ensaio sobre a impessoalidade
}

\author{
Pandemic ambiguity: an essay concerning impersonality
}

\section{Dax Moraes*}

Resumo: $O$ presente artigo consiste em uma tentativa de compartilhar algumas ideias no que tange à ambiguidade no atual contexto de pandemia. Embora não possamos de modo algum chegar a alguma solução, tampouco a uma resposta clara para cada um dos problemas envolvidos, certamente podemos colocar questões acerca dos limites da Política e das políticas de Saúde Pública. Por fim, podemos ainda pensar sobre a impossibilidade moral trazida por esse cenário.

Palavras-chave: Ambiguidade; Impessoalidade; Isolamento social; Pandemia; Espaço público

Abstract: The present paper is an attempt to spread a thought concerning the ambiguity in the actual pandemic context. Although we definitely cannot reach out any solution nor even a clear answer for the problems involved in, we surely may put some questions about the limits of Politics and Public Health policies as well. Finally, one can also think about the moral impossibility brought in by this scenery.

Keywords: Ambiguity; Impersonality; Social isolation; Pandemic; Public place

A primeira ocasião em que tomei ciência do novo coronavírus foi por meio de uma jocosa postagem em rede social que exibia uma cena (para nós, ocidentais modernos e assépticos) um tanto quanto repulsiva: uma moça oriental (aparentemente moderna) prazerosamente consumindo uma iguaria que consistia em uma espécie de caldo de morcego. De todo modo, aquilo a que se aplicaria o adjetivo "repulsivo" seria o fato de um morcego inteiro (que pode ser comigo ao final, conforme também mostrava a imagem) ter sido cozido com o ventre aberto.

Esse é um momento, antes de tudo, no qual se potencializa todo o clamor por "civilidade" que a certa altura se consolidou como a marca de nascença e selo de qualidade do "Ocidente". Qualquer pessoa atenta deve logo notar que essa fronteira não apenas consiste em uma demarcação cultural como, sobretudo, está muito para lá do Meridiano de Greenwich. O problema não é novo. Nesse sentido, é bastante peculiar o que Dostoiévski nos deixa ver em sua obra acerca do conflito entre ocidentalistas e orientalistas no contexto de busca por identidade por parte de uma nação que se estende ao longo do que fora convencionalmente estabelecido como dois continentes. A nação russa, junto à turca, justificaria a ideia de que o nome mais apropriado para aquela imensa massa de terra seria Eurásia, pois as pretensas "razões" geográficas para a distinção entre os continentes é, também, arbitrariamente cultural.

Mas nada disso constitui, por si só, uma ambiguidade. Talvez, antes sejam acidentes da política e da cultura. Outro acidente talvez seja o fato de que 2020 seja marcado pelo COVID-19. 2020, além de ter duplicado o algarismo 20, é um ano bissexto. Para sinalizá-lo, o nosso calendário é aumentado em um dia, mas há, por exemplo, o calendário judaico, cujos anos "bissextos" - melhor dizendo, embolísticos - podem ter um mês a mais, além de outras variações. Já o calendário chinês acrescenta um mês a cada três anos. 
Essas erráticas considerações iniciais ilustram, embora apenas de modo muito tímido, que a facilidade com que se pensa ainda em um cosmopolitismo, em um retorno da pax romana, é um sinal dos tempos. Segundo esse sinal, haveria uma possível solução política para os descaminhos do "mundo", mas o problema reside no pressuposto de que se trata de um só mundo, de que se deriva que uma única solução caiba a "todos e qualquer um”. Esse ponto de vista platonicamente universalizante e, portanto, despersonalizante, é a marca do "Ocidente" que mais e mais, recorrentemente, se vê ameaçado por aquilo que para ele é uma "barbaridade". Parece que o "Ocidente" está muito longe de uma pax com o "Oriente”, pois de nada vale chamá-lo para jogar conosco sob a condição de que sigam "nossas" regras, ainda que vivam em datas diferentes e segundo orientações espirituais bastante diversas. No entanto, sob a rubrica "humano", a cada vez se força todo outro a ser tal qual aquilo que pensamos de "nós mesmos". Essa fala unilateral do "Ocidente" que julga a si mesmo portavoz do humano em geral, que apelida uma doença emersa na China fazendo referência ao calendário cristão, na mesma medida em que des-singulariza "todo e qualquer" humano, consiste na pedra angular de toda ambiguidade.

A ambiguidade propriamente dita tornou-se um fenômeno político-midiático nos últimos tempos, vindo a ser o berço que acolhe o presente estado de pandemia. Em outras palavras, a pandemia mesma se vê atravessada pela ambiguidade do discurso que a acolhe e dissemina em escala e procedimento igualmente virais. A trágica ambiguidade do momento está impedindo um sem-número de pessoas de verem suas próprias inconsistências, bem como de enxergar a consistência de quem age de modo socialmente reprovável ou a moralidade de quem age de maneira individual ou coletivamente imprudente. Tudo tão ambíguo e terrivelmente paradoxal, mas, por trás de cada ato e opinião, se entrevê que cada um é egoísta e, assim, apenas aprova o próprio eco, seja da esperança, seja do desespero, sendo sempre o outro que, a cada passo, está prestes a colocar tudo a perder. Esse fenômeno que ocorre em toda parte e de todos os lados, sem qualquer fronteira clara de caráter ideológico, socioeconômico ou intelectual, também carrega o epíteto do "democrático", que, não obstante, é por muitos empregado no sentido de que a pandemia torna todos iguais (novamente). Uma coisa deveria ser certa se todo o resto não se passasse dessa maneira aqui descrita: que o que sobrou de Deus deixaria de existir... De todo modo, semelhante diagnóstico não pode passar sem maior exame e, para tanto, em primeiro lugar, deve-se perguntar o que significa, afinal, "ambiguidade".

Em Ser e tempo (\$37), Heidegger elenca a ambiguidade como um modo fundamental do discurso impessoal, daquilo que se diz e se reproduz sem provir de um autêntico si mesmo, ou seja, algo dito não por si mesmo, mas por outro. No contexto da obra, o tema se segue ao da falação vazia que reproduz o "ouvir dizer" ou "assim se diz" e ao da curiosidade, que também marca o fenômeno midiático contemporâneo. O que desperta a curiosidade, o tornar antigo tudo o que acaba de ocorrer a fim de assim, saturando o presente, criar a expectativa pela novidade, só se alcança mediante a ampliação desmedida do "espaço público". As mídias em geral têm aí um papel decisivo, pois permitem a reprodução de um verdadeiro mercado saturado e igualmente insaturável de informações. Não se tem tempo para pensar, nem mesmo para querer, tampouco para viver, nada restando senão deixar-se levar pelo fluxo de dados. O fenômeno contemporâneo chamado de "Era da Informação" nos tira de nosso mundo retendo-nos no mundo das representações de mundo meticulosamente selecionadas e igualmente aleatórias, postas em frenética sucessão de modo que soem espontâneas e igualmente "verazes".

Tudo aquilo com que, de hora a hora, os meios de informação atuais excitam, surpreendem, estimulam a imaginação do Homem - tudo isso está hoje mais 
próximo do homem do Homem do que o próprio campo à volta da quinta, do que o céu sobre a terra, do que o passar das horas do dia e da noite [...] $]^{1}$.

O interesse dessa reflexão inicial, portanto, consiste na abertura de uma reflexão sobre o fato de que a pandemia instaura e instala como nunca, no contexto de uma "Era da Informação", o mais decisivo desenraizamento do humano em relação a seu mundo e seu inevitável transplante para o mundo das representações e do subjetivismo. O meu vizinho, o que se passa ou pode se passar comigo, o que devo e não devo, o que pertence a todos e o que não pode ocorrer a ninguém, tudo isso é mediado, tudo me vem por uma tela, por uma tela eu mesmo levo a mim e meu discurso a outrem. Tudo chega de um lugar qualquer, se dirige a todo lugar, e assim é e deve ser "em todo o mundo" e "para todo mundo", sempre apresentado como aquilo que as pessoas mesmas pensam, sentem e fazem, como se a soma das subjetividades resultasse em tudo o que há de mais objetivamente real a se saber. Assim, é pela multiplicação infinita de subjetividades espalhadas por todo o mundo, saturada em todo o mundo, tornada insaturável pela produção de um pretenso autorreconhecimento universal nas telas midiáticas, que o mundo das representações se torna o único espaço possível de compartilhamento, palco da alienação de cada um em todo outro.

Isso considerado, detenho-me aqui na "ambiguidade". Trata-se de não mais se poder "distinguir, na compreensão autêntica, o que se abre do que não se abre", um fenômeno cotidiano que "se estende [...] à convivência como tal" e ao ser de cada um em relação a si mesmo $^{2}$.

Um elemento fundamental, se não mesmo originário, que se abre na mesma proporção em que imediatamente se oculta, é precisamente aquilo que menos se diz "de si", apenas "do outro", aquilo que, enquanto afirma, nega, e enquanto oferece, retira, aquilo que, a fim de não soar "ofensivo", pode ser denominado "privação do cuidado", que se revela sob as mais diferentes faces, sobremaneira, talvez, na substituição do outro em seu cuidado. A pandemia propriamente dita se faz discurso pandêmico e vice-versa em uma recursividade infinita. $\mathrm{O}$ encobrimento dessa ambiguidade consiste no que "publicamente [...] se esconde, e o impessoal haverá sempre de objetar que essa interpretação não corresponde ao modo de ser da interpretação do impessoal"3.

Um exemplo concreto desse fenômeno pode ser encontrado na interpretação que o impessoal (ou discurso público) oferece para a condição de confinamento. Provavelmente não é necessário objetar o uso do qualificativo "voluntário", por trás do qual se oculta uma recusa à patente coercitividade da conjuntura - cada um quereria estar fazendo outra coisa que não o que está fazendo se... (logo, seguindo um imperativo hipotético) - ao mesmo tempo em que pleiteia para si mesmo todo o acervo de condições morais, tais como autonomia, desprendimento e assim por diante, já negadas pelo caráter "se... então" inerente à condição de isolamento social, esse "autoexílio" ditado por questões de saúde pública. Por sua vez, revela-se que o "lá fora com o outro" não é um bem em si, mas algo de que se prescinde mais facilmente do que o esperado desde que aquilo "para-que-serve" esse lá-fora venha a ser garantido. A exigência de serventia da normalidade talvez seja mesmo o inaudito e inesperado contrafactual de todo o pandemônio que o cinema americano buscou "prever" para uma situação como esta pela qual o mundo está passando. Como é possível que o mundo já não tenha sucumbido à brutalidade dos saques, incêndios e todo tipo de atrocidades, nem mesmo a suicídios rituais ou à caça sangrenta a possíveis portadores da doença - enfim, ao que se viu nos filmes?

\footnotetext{
${ }^{1}$ HEIDEGGER, Serenidade, 16.

${ }^{2}$ HEIDEGGER, Ser e tempo, 237.

3 HEIDEGGER, Ser e tempo, 239.
} 
Schopenhauer, em um célebre passo do primeiro volume de $O$ mundo como vontade e representação $(\$ 62)$ no qual oferece pela primeira vez sua posição com relação a Direito e Política, traz um discurso que, para a sensibilidade moderna, tende a soar bastante repulsivo, para dizer o mínimo. Aliás, o tom hobbesiano, por si só, fere nossos ouvidos. A tese, à primeira vista, apenas enfatiza aquilo em que se sustenta o ideário liberal, porém exposto de maneira pouco simpática, a saber: que o papel do Estado consiste em manter em sociedade indivíduos egoístas por natureza, que buscam apenas o próprio bem e o dos seus, e que isso só pode ser feito na medida em que o Direito ofereça certo grau de satisfação do egoísmo. A sociedade é um pretenso espaço de realizações que só podem vir a bom termo na medida em que cada um encontre nela possibilidades suficientes de ter seus interesses garantidos, em que cada um reconheça ter ao menos direitos a obter o que deseja e, por fim, que considere minimamente justo seu próprio fracasso individual. É evidente que este último item é o mais controverso, a despeito de ser o mais decisivo - eu o formulo por minha conta e risco -, mas o que precisamente faz a ideologia meritocrática é incutir em cada um, desde a mais tenra idade, por obra dos próprios pais já seduzidos, que seu fracasso se deve a esforço relativamente insuficiente e, se tal fracasso puder ser imputado a algum fator extrínseco, que se deva recorrer às instituições. Trata-se da necessária domesticação dos afetos e recalque da violência pela oferta de contramotivos igualmente atentos ao egoísmo. Em síntese, a sociedade se constitui sobre uma complexa teia de crenças que convergem no seguinte ponto: de que o mundo sem sociedade é impossível. Mas: que sociedade? Uma sociedade como a nossa é permeada por anseios e ambições tão elevadas a ponto de que nenhum indivíduo consiga imaginar-se como bastando a si mesmo, de maneira que o sentido do "lá fora" não é nada menos do que minha própria sobrevivência. Aqui, não basta ter em conta a famosa fábula dos porcos-espinhos.

Diante dessa hipótese, retornemos ao ponto. Há exceções muito curiosas e quase despercebidas no discurso impessoal sobre a interpretação do autoconfinamento (ao passo que, como já aludi, consiste mesmo em confinamento ditado por uma conjuntura, uma medida pautada em interesses e não-moral em si mesma). Tais exceções ressoam quando alguém coloca verbalmente o proteger a si mesmo à frente do proteger ao outro. Flagra-se no olhar um instantâneo constrangimento. Da outra parte, a fala pública diz para proteger, cuidar do outro. É evidente e inegável que aglomerações são um mal coletivo, global mesmo, mas não se trata aqui de julgar o efeito e a utilidade dos meios, mas apenas de refletir acerca da ambiguidade narrativa. Com que finalidade? Buscar compreensão e clareza para uma (talvez impossível) compreensão da impessoalidade que nos atravessa a cada um de nós; em alguns, mais, em outros, menos. Enfim, uma impessoalidade que é por vezes recusada em um aspecto, mas ainda em nome de outro, sendo, contudo, invariável esse caráter de "em nome de algo".

O discurso padrão, em uma formulação livre, diz que se deve aderir a um isolamento com relação a quem habita outra residência, eventualmente se estendendo àqueles que coabitam a mesma residência. A interpretação do discurso não é formulada a posteriori, mas embutida no próprio discurso a título de justificativa: assim se previne o contágio e, mais importante, protege-se o outro. O elemento da proteção ao outro vem legitimado no ideal de sociedade que, desacreditado, na pandemia, diz a si mesmo que ainda vive. Trata-se da fraternidade, fundada na igualdade, garantia de liberdade. A salvação do espaço público reside, porém, agora, em seu esvaziamento. A política adquiriu uma agorafobia e sua praça, paradoxalmente, perdeu espaço para o ciberespaço ilimitado da mídia, um infinito de possibilidades apaziguadas pelas comodidades do lar - para quem as adquiriu, é verdade. Quem persiste no espaço público convencional, que, de fato, não se restringe ao discurso, torna-se inimigo público e ameaça iminente. No Brasil, com sua famosa cordialidade, tão 
famosa que frequentemente se esconde aos olhares curiosos, encontrei uma pessoa que personalizou sua foto de perfil no Facebook com a frase "Fique em casa, seu arrombado", uma ofensa alusiva à homossexualidade masculina aqui empregada em nome... da saúde pública, da "solidariedade", do "humanismo". Como essa expressão é, até onde sei, tipicamente carioca, bastante antiga e eu acreditava estar em desuso no século XXI, talvez seja necessário esclarecer que seus sinônimos, não por acidente, são intercambiavelmente "seu merda" e "seu viado", porém me poupo de explicar o porquê. O que tal pessoa pensa de si mesma, do outro, do espaço público, são questões que por si sós mereceriam uma discussão à parte. Mesmo em outras regiões "mais civilizadas" do planeta, esses "sabotadores" são ofendidos, xingados, expulsos do espaço público, tornando-se objetos de todo tipo de pré-julgamento, isso para que "nós", "os humanos solidários", tenhamos a perspectiva de voltarmos todos a ocupá-lo. Mas esse é apenas o espaço geográfico. Acontece que, com ele, perde-se o que até então se entendera como espaço social, não apenas em nível econômico em que se desempenha uma função, mas em nível afetivo.

Há muito de "interessante" a se observar aqui. Em primeiro lugar, que a liberdade produza o desejo de isolamento, que a igualdade exija o mesmo de cada um, que a fraternidade exija a migração para o espaço virtual e midiático ao qual muitos ainda se mostravam relutantes ou, pelo menos, parcimoniosos. Enfim, que os três elementos, reunidos, prossigam potencializando a violência em nome da paz. Um clamor disseminado pela distância dos entes queridos confunde-se frequentemente com a sensação de vazio perante a ausência de movimento de pessoas estranhas que nos distraía, não porque prestássemos atenção a elas, mas justamente porque não prestávamos atenção alguma. De outro lado, pessoas se veem obrigadas a enfrentar as agruras do convívio ininterrupto com seus coabitantes. O tédio que emerge revela o desinteresse inaudito de tantas pessoas por aqueles com quem acreditavam conviver quando, em verdade, se evadiam de suas relações íntimas sem perceber. Assim como o silêncio súbito revela que até então havia sons, o esvaziamento social revela quanta gente não recebia atenção enquanto cada um de nós fazia seu percurso cotidiano pelas vias das cidades ou se movia no interior da própria residência. Não é de se estranhar que uma preocupação econômica emerja. O espaço social afetivo já vinha sendo substituído por aplicativos... O que mais se quer saber do outro é se está engajado na proteção "do outro", isso por que eu mesmo sou um outro para ele. Produz-se em toda parte a vigilância e o controle, mas, muito embora não seja assim que em geral se interpreta o que ocorre, releva-se a natureza essencialmente ambígua de toda convivência pública, mesmo com as ruas cheias.

Todo mundo presta primeiro atenção em como o outro se comporta, no que ele irá dizer. A convivência no impessoal não é, de forma alguma, uma justaposição acabada e indiferente, mas um prestar atenção uns nos outros, ambíguo e tenso. Trata-se de um escutar uns aos outros secretamente. Sob a máscara do ser um para o outro atua o ser um contra o outro ${ }^{4}$.

É estranho como, por exemplo, são invisíveis os trabalhadores da limpeza até que se constate que não estejam fazendo seu serviço a contento, pois aqui não se tem em vista alguém em particular, assim como se dá ouvidos ao que se diz sem dar atenção a quem está dizendo, ou, pelo, contrário, não se dá atenção ao que está sendo dito, mas a "quem" o diz, ou melhor, seu "lugar de fala", sempre genérico. Se, até então, isso não era claramente compreendido pelo impessoal, agora se encontra ainda mais encoberto, justamente porque chegou ao primeiro plano. Antes, ninguém "tinha" de "tomar conta do outro" e então

${ }^{4}$ HEIDEGGER, Ser e tempo, 239. 
corriqueiramente o "ignorava"; agora, passa-se precisamente o inverso. Por que "um contra o outro"? A resposta aparece retumbante em sua auto-ocultação: porque a presença do outro "ali" há de fazer perdurar a "nossa" aqui, o "ir e vir" do outro é o prolongamento de minha reclusão.

É patente que o outro não é protegido por mim desde que eu não esteja infectado. Aquele que representa risco para o outro que insiste em se arriscar no espaço público geográfico é um outro qualquer. Por isso qualquer um é uma ameaça. A impessoalidade é também patente. Quanto a mim, devo exigir que todo outro retire-se no interesse da reocupação, que deverá vir tão breve quanto possível, e isso significa: antes que se extingam os recursos que permitem o meu próprio autoconfinamento até então "voluntário". Este deixará de sê-lo tão logo a conjuntura se agrave em tal medida que eu, por causa do outro que saiu voluntariamente, seja agora obrigado a sair. Isto é, ir em busca dos recursos por mim mesmo, precisamente quando o perigo estiver realmente em toda parte e incontrolável.

Cabe aqui mais uma consideração da ambiguidade que complementa esta última. Diz respeito àquilo que viabiliza o autoconfinamento: que incontáveis pessoas não se isolem, mas se conservem disponíveis, como instrumentos. E não se trata apenas de farmácias, hospitais e mercados. O modo mais seguro de sair é em meios de transporte particulares. Isso muitas vezes exige oficinas e postos de combustíveis, até porque não somos um país em que vigore a cultura das bicicletas e patinetes. Há uma série de demandas relativas a possíveis emergências residenciais, não redutíveis a questões de segurança pública. Onde ficam as tabacarias, ou mesmo os pontos em que os trabalhadores se alimentam de pratos frescos para não terem de comer marmitas preparadas na véspera? Seriam dispensáveis ou contribuiriam para alguma saúde espiritual? Até que ponto é possível conduzir uma terapia psicanalítica ou psiquiátrica e a que pacientes isso pode bastar? Quanto tempo uma pessoa com lesões físicas ou males cerebrais pode ficar privada dos equipamentos de sua terapia, que impeçam a atrofia de seus membros ou o desenvolvimento de suas faculdades? Mas isso não é o bastante. Higienizar tudo o que se adquire não é tarefa fácil, quiçá uma atividade impossível de atingir a perfeição junto à imensa maioria que toca a vida a base de placebos. O risco de ir a um mercado é imenso, "apenas um por residência" deve se arriscar por vez, junto àqueles incógnitos que não saem à rua apenas em caso de necessidade e o mínimo possível. Por sua vez, e justamente por isso, muitos se apoiam nos subempregados que se arriscam por necessidade em levar todo tipo de coisa nas residências de quem está lutando contra a peste. A matemática é perversa. Um pequeno grupo faz entregas em um semnúmero de residências entrando em contato com o maior número possível de potenciais contaminados que, no entanto, tentam se conservar a salvo.

Do ponto de vista prático, é o menor dos males se pesado na balança junto a um membro de cada uma dessas residências tendo de sair de casa para prover-se de seus próprios suprimentos. "Ponto de vista prático" significa, aqui, o mesmo que "ponto de vista público/impessoal". O entregador é "ninguém”. Do ponto de vista mais propriamente humano, cada qual não deveria ser responsável pelo próprio risco e o de seus coabitantes? Não tenho a pretensão de responder. Apenas sugiro que, ao contrário do que se pensa, a política não pode oferecer resposta humanamente satisfatória, precisamente porque seu interesse é o interesse "de todos". Mas é nessa fratura que penetra o discurso sobre a vulnerabilidade do mais fraco, que tem algo de correto: que a conjuntura não nivela, não iguala, antes aprofunda como jamais a desigualdade preexistente. Em nome do menor risco, em um cálculo frio e, portanto, inumano, os mais necessitados são coagidos a enfrentar riscos em nome de desconhecidos, colocar em risco os seus coabitantes, quando poderiam, se suas condições materiais o permitissem, correr tanto risco quanto qualquer outro, o que só é possível se cada um se incumbir de prover a si mesmo e aos seus com os suprimentos 
necessários. Se digo, portanto, que não tenho resposta a dar é porque o círculo não tem começo nem fim, a não ser quando se inicia e se termina seu desenho - depois, não tem volta -, porém, isso como que já nos foi dado na conjuntura. Por mais que a emergência atual se dissolva, caia no esquecimento ou vá parar em livros de história, vire filme ou não, não surge no horizonte uma solução humanamente possível, tampouco a promessa de um ajuste de contas com a natureza ou com os desfavorecidos, justamente porque a natureza está contra nós desde que não nos reconhecemos nela, em virtude da alienação constitutiva de nossa existência fora de nós mesmos, e o desfavorecimento dos desfavorecidos é ainda o combustível que promete manter tudo de pé. Assim, antes da ameaça mortal, a pandemia já colocara implicitamente a natureza ambígua de nosso comportamento impessoal que faz dessa ameaça sua justificativa encobridora.

A propósito, há rumores de cidades no mundo em que animais selvagens ou silvestres começam a (re)aparecer em virtude da redução do barulho, do movimento e da poluição, como os golfinhos em Veneza - este caso já desmentido pela National Geographic em publicação no último 24 de março. Espera-se que haja algum prenúncio de uma retomada da harmonia, mas não seria, acaso se realizasse, o prelúdio de uma nova expulsão em caso de a sociedade humana sobreviver? Como haverá de ser essa reocupação? Curioso como muitos se arriscam não apenas com relação a prognósticos, mas também com relação a causas. Surgem discursos vários, ora sensatos, ora extravagantes. A cada vez se procura confirmar teses pré-concebidas, como em um esforço último por angariar adesões, seja com relação ao futuro, seja com relação ao passado, pois o presente está vazio. A espécie humana, ao menos no Ocidente, carrega uma profunda má-consciência, e hoje se vê repetir-se aquilo que o agente Smith diz a Morpheus quando o interroga em Matrix: a única categoria em que a espécie humana pode ser classificada é a de um vírus. Quem, ao ver o filme, não disse a si mesmo "Era isso mesmo o que eu estava pensando"? Ou ainda "Ele é o vilão, e isso não me importa, eu faço a minha parte e confio no ser humano"? Tudo isso parece dizer que não saímos do lugar, encarcerados em um círculo mais perverso do que os limites do confinamento, já que o precede. O diagnóstico cruel é posto na voz do vilão para que consigamos lidar com a verdade, afastando-a de nós.

Heidegger também escreve: "A ambiguidade da interpretação pública proporciona as falas adiantadas e os pressentimentos curiosos com relação ao que propriamente acontece, carimbando assim as realizações e as ações com o selo de retardatário e insignificante."5. Nesse sentido, não estaria eu mesmo imprimindo esse selo na fala ambígua do impessoal? Provavelmente. Certamente. Mas o que seria reconhecer-lhe a significância? Compreendê-la como tal?

O fato é que não se sabe o que é essencial e o que não é. A ordem vigente se perde no círculo há pouco descrito e não encontra saída senão o atendimento a demandas. Mas, enquanto isso, além daqueles que dedicam a própria vida a salvar vidas, há uma multidão inumerável e sem rosto que "não estava aí pra isso", quem trabalha no provimento das famílias para que elas não tenham de precisar daqueles que se dedicam a salvar vidas, "que estão aí pra isso". No entanto, além de não receberem aplausos, mas serem vistos como sempre foram - invisíveis -, vivem o risco quarenta horas por semana - esta é a sua "quarentena" - e o levam para suas próprias casas. É evidente que não me refiro a proprietários tentando manter seus negócios, mas aqueles que estão ao seu serviço para que atinjam a meta. Há alguns dias encontrei em um mercado um repositor que "não estava aí pra isso", mas que sabia disso, e dizia: "Deviam estar todos em casa antes que seja tarde e todos queiram sair e não possam”. Impressionante e veraz como o profeta anônimo a quem

${ }^{5}$ HEIDEGGER, Ser e tempo, 239. 
ninguém dá ouvidos. Transtornado com as pessoas que esbarravam nele enquanto repunha mercadorias desejadas por aqueles que se aglomeravam à sua volta, dali a poucos minutos, deixava cair uma torre de caixas no chão, uma das quais estourando, obrigando-o a agacharse e guardar de volta pacotes de salgadinhos. Salgadinhos são necessários? Sim, como nunca! Mas o repositor preferia ser obrigado a se isolar a ser obrigado a não se isolar e é apenas isso o que há de voluntário no autoconfinamento, porém isso, como toda liberdade civil, não é para todos, antes depende do quão igual se é aos demais... Quem tem o cânon na mão? Ninguém - isso também já se decidiu.

O problema econômico que a tantos preocupa é visto por outros como algo superficial, algo que, ao contrário de vidas perdidas, se recupera. O que há de mais humanamente legítimo nessa preocupação é que parece ter sido antecipadamente decidido o que pode e o que não pode ir à falência, quem pode e quem não pode perder seu emprego. Não é necessário dizer que pequenos negócios são mais frágeis e que, por outro lado, grandes negócios permitem ficar na rua o menos possível e o mais distanciado dos demais. A política pública já decidiu, não de modo expresso, tampouco tácito, mas por sua própria natureza pública, impessoal, isonômica. Essa bizarra convergência de política e egoísmo institucionalizado é o que dá a impressão de que toda pessoa de bom senso sabe o que fazer ou com quem se informar, o que supostamente legitima a perseguição de toda dissidência. "Tudo parece ter sido compreendido, captado e discutido autenticamente quando, no fundo, não foi. $\mathrm{Ou}$ então parece que não o foi quando, no fundo, já foi." ${ }^{6}$. Acontece que essa discussão se verifica sempre no contexto do "ouvir dizer", pois se trata sempre de obter informação, uma tendência à ausência de pensamento e de autonomia, calcada em um cálculo unilateral (impessoal) de probabilidades, que não representa nada menos do que "o modo mais traiçoeiro em que a ambiguidade propicia à presença [Dasein] possibilidades, a fim de sufocá-la em sua força"7, o que significa estarmos a cada vez entregues àquilo que se deve fazer ou não fazer. Ora, "uma coisa é termos ouvido ou lido algo, isto é, termos tomado conhecimento disso, outra é conhecermos, isto é, refletirmos sobre o que ouvimos e lemos" 8 , mas também, cada uma das facções já tem decidida a fonte de suas informações e se aferra à sua pretensa autoridade para inibir quaisquer outras, sempre em nome do país, em nome da humanidade, em nome do mundo, em nome de algo que já estava aí, já foi dado e ao qual cabe à gente se adequar.

Outro fator de ambiguidade parece ainda mais crítico. Acima foi mencionado o caso majoritário daqueles isolados que se encontram saudáveis. Há de se considerar, também, o dos infectados. Estes, sim, sem ressalvas, são passíveis de isolamento e quarentena. Mas, diante disso, o que se faz - repito não ser minha pretensão declarar uma resposta ou solução - é dizer-lhes para não procurarem atendimento médico em caso de sintomas suspeitos, a não ser que precisem de instalações hospitalares para que se mantenham estáveis. Provavelmente morrerão em tais condições, mas sob a vista de um órgão público que saberá dar cabo de seus corpos. Isso é decidido com base em impessoal cálculo de probabilidades que resulta em que os Sistemas de Saúde não haverão de comportar a explosão da demanda por seus serviços. Na ausência de tal cálculo, prevaleceria, talvez, um bárbaro "direito de primeiro ocupante" para leitos hospitalares, unidades de tratamento intensivo, respiradores e - também - um precoce aumento de profissionais de saúde submetidos a condições de risco antes mesmo de "nossa" necessidade deles chegar ao nível crítico. Ao lado disso, certamente há quem faleceu sem ter seus sintomas aliviados, há quem foi privado do

\footnotetext{
${ }^{6}$ HEIDEGGER, Ser e tempo, 238.

7 HEIDEGGER, Ser e tempo, 238.

${ }^{8}$ HEIDEGGER, Serenidade, 21.
} 
cuidado social pela política que guarda sua (pouca) munição para o momento crucial, o ápice da curva. (A falação chega a exigir que eu me desculpe por empregar um termo alusivo a uma guerra, muito embora não fosse minha intenção fazer semelhante analogia.) Dizer e redizer nas mídias que o número de vítimas é muito maior do que o divulgado torna ambígua a contenção de pânico por parte de instituições que mantêm a população nas sombras, também revela a ausência de controle, por parte dessas mesmas instituições, com relação aos casos em que impera a lei da natureza, pois o que a sociedade construiu com tanto empenho para garantir a si mesma está sendo preservado para aqueles que resistirem por mais tempo - e quem serão esses? Sobre tudo isso, todo mundo já tem "algo a dizer".

Quando se fala em desigualdades sociais, sempre se pensa, por exemplo, em Marx. Uma das teses que Marx nos oferece busca elucidar a relação entre trabalho, tempo e reprodução das condições de vida. Sua ênfase era o fazer e o produzir, bem como a destinação dos produtos do trabalho. A tese liberal em torno do direito de propriedade também havia estabelecido uma relação intrínseca ou mesmo essencial entre o direito à posse e o grau de esforço na obtenção do bem. Em ambos os casos, estamos diante de apreciações meramente materiais (ao menos assim se anunciam) do pertencimento de algo à força que o tornou disponível. Propositadamente, não me detenho aqui no que Marx tinha a dizer sobre os meios de produção, pois o ponto ao qual pretendo chegar não passa por aí, precede-o. Detenho-me na questão da relação entre a força produtiva como tal e nossos meios de apropriação de seus produtos, sendo secundário se se trata de bens de consumo imediato ou meios de produção. Sobre isso, parece passar despercebido um elemento metafísico que Schopenhauer observou no mesmo capítulo já referido de $O$ mundo como vontade e representação. Diz ele em defesa do caráter moral do direito à propriedade:

Porque, de acordo com nossa elucidação da injustiça, a propriedade [Eigenthum], que não será roubada do homem senão injustamente, consiste apenas naquilo que é modificado [bearbeitet] por suas forças, aquilo cuja subtração subtrai, portanto, as forças de seu corpo, a vontade objetivada nele, a fim de fazê-la servir à vontade objetivada em outro corpo. Pois somente assim, pela tomada [Angriff] de uma coisa sem vida, completamente diferente do corpo vivo de outra pessoa [fremden Leibes], o praticante da injustiça invade a esfera da afirmação da vontade da outra pessoa, já que essa coisa é, por assim dizer, intrinsecamente unida e identificada com as forças, o trabalho do corpo vivo de outra pessoa. (W I, § 62, 396. Tradução minha.).

Depreende-se dessa consideração moral metafisicamente fundada que, ao fazermos uso de algo que não consista na exteriorização de nossas próprias forças vitais, fazemos uso de força vital alheia. Fazemos isso todo o tempo, eu mesmo agora enquanto escrevo. Minha força vital foi convertida em unidade monetária de troca pela qual obtive o computador de que faço uso, bem como tantas outras coisas essencialmente idênticas ao trabalho de quem, com suas forças, as produziu. Há pessoas cuja força vital não vale quase nada no mercado de trabalho e jamais conseguirão obter o que eu obtive e ainda virei a obter. Nem Locke, nem Marx, nem ninguém pode resolver esse impasse. Mas que impasse? O sem-número de vidas que consumo agora enquanto escrevo este artigo, em casa, enquanto outras forças se exteriorizam, transformando matéria a ser trocada comigo, essas vidas que estão aqui materializadas sob o meu poder. Não posso ter para mim "as almas" dessas pessoas, mas posso me apropriar e me aproprio do que são capazes de produzir, e isso significa o mesmo, pois assim me aproprio de suas vidas, coloco seu ser a meu serviço, não apenas o seu tempo ou seu direito. Um sem-número de forças anônimas que vivem por mim enquanto vivo por elas, que permanecem mudas enquanto comunico aqui minhas ideias. Assim é com todo o 
resto. Quando se fala em "troca”, pretende-se indicar algum grau de consentimento, logo, não se trataria de uma "invasão injusta" do domínio da "esfera da afirmação da vontade da outra pessoa”. Entretanto, se vamos um pouco além, não muito, logo podemos compreender a custa de que cada um de nós vive quando ninguém mais provê a si mesmo daquilo que deseja e precisa. De fato, na ponta oposta da corda, suponho que a força vital de quem produziu cada pedaço de plástico de que faço uso, de cada alimento que ingiro, também foi objeto de troca, não de usurpação. De todo modo, como salienta Schopenhauer mais adiante, não é apenas por violência e usurpação que invadimos a esfera da vida do outro, mas também pela astúcia. E que será o contrato de trabalho se não uma astúcia pela qual alguém é convencido a trocar ou mesmo doar sua própria vida como se isso fosse sua própria vontade, isto é, não fazer uso de sua força apenas para si e para os seus como quer a natureza. Mas o que o faz pensar assim, tornando-se assalariado ou mesmo um escravo? Pensar que essa alternativa, para o momento, é melhor do que outra, dando a própria vida a outrem para continuar a viver. Se... então... Aqui, no altar da convenção, caem juntos a Política e o Direito para que surja um pensamento propriamente moral.

Haverá, portanto, moralidade possível em uma pandemia?

$\mathrm{Na}$ tentativa de elucidar uma provocação feita de início, quando fiz menção a um agir de "modo socialmente reprovável" e à "moralidade de quem age de maneira individual ou coletivamente imprudente", eu diria algumas palavras adicionais. É socialmente reprovável agir de acordo com convicções religiosas em uma sociedade como a nossa. O que se espera de alguém que, de todo o coração e desde o fundo de sua alma pia, crê na salvação por seu Deus e no vínculo místico de um sacerdote com seu Salvador? Que acorra a ele e siga sua missa. Esse cidadão pio, no entanto, deve crer nos homens a ponto de poder prescindir do poder divino em que apostara toda a sua fé resignada. Afinal, não somos mais "os bárbaros” que pintam suas casas com sangue antes da passagem do anjo da morte... Um padre vai à internet ensinar a usar o álcool em gel e pedir que o fiel não vá à igreja. Nem Deus pode salvá-lo da imprudência e essa é sua fé. Eis o que quis dizer com "deixar de existir o que sobrou de Deus". Como compreender que a comunhão pretendida em uma missa pode ser mediada por rádio ou televisão? O Templo está morto e quem acorre a ele, aglomerando-se, é inimigo público. Nesse contexto, somente a diáspora pode dar uma sobrevida ao nome de Deus, como presença fantasmagórica que cessou de fazer milagres e permitiu o Holocausto. Até que ponto é papel da sociedade julgar, proibir, ou ofender a multidão que vai ao culto? Caberia exigir que, então, permanecem lá dentro em quarentena? Não, pois, em tantos dias, um infectado contaminaria dezenas ou centenas, e isso a sociedade não quer, não quer a "ignorância” de crer sem razões ou mesmo contra as razões. Mas com que cara aquele pio pretende encarar seu Deus? Deve ser permitido a Deus queimar seu próprio Templo e dizer, do alto de uma cruz, que o Reino está em nós. Já a imprudência de ser moral consistiria em ser capaz de arriscar-se no afeto, no cuidado do outro, mas isso é impossível. Pois o outro, se infectado, talvez só apresente sintomas depois de decorridas duas semanas. Devo protegerme dele para não passar o mal adiante. A quem? Aos meus, aqui comigo, longe do outro.

Que não ocorra algo análogo ao que se passa com Raymond Rambert, personagem de Camus, que muito tarde se deu conta de que, em sua ânsia de romper o isolamento pela peste para, enfim, voltar para junto de sua esposa, acabara esquecendo-a em meio a todo seu esforço para encontrá-la, pois este tinha se tornado seu único pensamento ${ }^{9}$.

${ }^{9}$ CAMUS, A peste, 145. 


\section{Referências}

CAMUS, A. La peste. [S.1.]: Gallimard, 2005.

HEIDEGGER, M. Serenidade. Trad. Maria Madalena Andrade e Olga Santos. Lisboa: Instituto Piaget, [2000].

HEIDEGGER, M. Ser e tempo. Trad. rev. Márcia Sá Cavalcante Schuback. 9. ed. Petrópolis: Vozes; Bragança Paulista: EDUSF, 2014.

SCHOPENHAUER, A. Schopenhauer im Kontext: Werkausgabe I. Berlin: Karsten Worm InfoSoftWare, 2001. 1 CD-ROM. 